\title{
The Rise of Technocapitalism
}

\author{
Luis Suarez-Villa
}

\begin{abstract}
The rise of technocapitalism involves the commodification of knowledge in faster and more diverse ways than at any previous time in human history. This article provides insights from a macro-analytical perspective on the phenomena that mark the emergence of technocapitalism as a new form of market capitalism, and their influence on the commodification of knowledge for invention and innovation. The phenomena in question involve the rapid accumulation of inventions and of knowledge-sensitive infrastructure. The rapid reproduction of creativity and a faster diffusion of knowledge, both of which have been supported by a massification of technical education, are also important for the emergence of the new era.Their contribution to the commodification of technological knowledge is most obvious in the pervasive corporatization of invention and innovation, and even more so in the emergence of continuous invention and innovation as a standard component of corporate strategy.
\end{abstract}

Keywords: technocapitalism, knowledge society, commodification, innovation

Technocapitalism is an emerging form of market capitalism, rooted in invention and the development of new technologies. Various phenomena mark the rise of this new epoch and are harbingers of major changes in the social and economic structures of the twenty-first century. All of the identifiable phenomena have substantial implications for the modes and means through which knowledge is used and commodified.

Unlike the raw materials and labour power, which were the main resources of industrial capitalism, technocapitalism relies greatly on intangibles. Such intangibles as knowledge and creativity are the most valuable resources of this emerging new era. As a result, the new industries and activities that have risen in recent years are far more dependent on intangibles than any of their predecessors.

Technocapitalism is replacing the reproduction of capital as the most important function of society with the reproduction of knowledge. Capital has become more ubiquitous than ever in human history, to the extent that theories and models based on its scarcity, formulated as recently as three decades ago, have become obsolete. On the other hand, the scarcest resources today are knowledge and creativity. They are scarce pre- 
cisely because they can only be acquired over long periods of time and through enormous effort and persistence.

More than ever, it seems that the accumulation and reproduction of technological knowledge will decide which societies prosper. Those that emerge at the top of technocapitalism's global hierarchy will be the ones that can build up and reproduce new knowledge more effectively. No society that expects to prosper in this emerging new era can escape this imperative, in much the same way that those which advanced into industrial capitalism during the nineteenth and twentieth centuries could avoid assimilating its premises.

The emergence of the so-called knowledge society is an important outcome of technocapitalism. The reproduction of knowledge is at the core of this phenomenon, and is as fundamental to the new order as raw materials and the reproduction of capital were to industrial capitalism. However, for knowledge to be reproduced it must first become a commodity. Commodifying knowledge is therefore a vital prerequisite for it to gain any exchange value. Under technocapitalism, knowledge assumes the properties of a private commodity, much as raw materials or labour power did under industrial capitalism. Capital, raw materials and labour power are therefore relegated to a less important plane.

As the commodification of knowledge deepens, technocapitalism places it at the service of economic gain more than at any previous time in human history. Today, technological knowledge and creativity account for more than two-thirds of the value of most products and services, and its total value is already greater than that of physical capital in every ad- vanced society. It should therefore not be surprising that the newest and most innovative activities, such as biotechnology, software design, microelectronics, advanced computing, bioinformatics or nanotechnology are more dependent on new knowledge and creativity than any of the industries spawned by industrial capitalism. By and large, therefore, we are witnessing a major transformation of society that is highly dependent on commodified knowledge, deployed to suit the profit motives of the agents of the new order.

This contribution will provide a succinct overview of several phenomena, which support the emergence of technocapitalism. The first set of phenomena to be considered involves long-term processes of accumulation. The accumulation of inventions and of knowledgesensitive infrastructure has been of fundamental importance for the emergence of technocapitalism, and all of the other phenomena that are part of this process of change rely greatly on them. A subsequent section will consider a set of phenomena related to processes of diffusion and reproduction. The massification of education, diffusion and corporatisation of technological knowledge, and the rising importance of continuous innovation are all vitally important to the emergence of technocapitalism, and to the new forms of knowledge reproduction and commodification that it is spawning. A final section will then provide some reflections on the emergence of the new era and its social implications.

\section{Processes of Accumulation}

The first set of phenomena supporting the rise of technocapitalism involves ac- 
cumulation. Much as the accumulation of capital in the nineteenth century was fundamental for the emergence of industrial capitalism, the rise of technocapitalism depends greatly on two distinctive processes of accumulation. Both of these processes are long-term in nature and their importance can be seen by examining some specific trends in the twentieth century.

\section{Invention}

A very large and rapid accumulation of inventions during most of the twentieth century provided a fundamental platform from which the new era is emerging. At no previous time in human history were so many new discoveries and ideas found, introduced and made to work in practical endeavours. The new discoveries provided an enormous and increasing stock of knowledge from which other new discoveries could be spawned.

Figure 1 provides evidence on the long-term accumulation of inventions that has underpinned the emergence of technocapitalism. The graph shows the total number of invention patents that were legally valid and available for use in the United States, in any given year between 1880 and 1995. In order to receive a patent, any idea or discovery must pass a rigorous and lengthy evaluation of its novelty. A satisfactory evaluation that leads to a patent award can then serve as a benchmark of invention and its accumulation over time. The indicator shown in Figure 1 therefore constitutes the total number of unexpired patents that are legally available for use in any activity. This measure was designated as the innovative capacity, mainly because it comprises the total stock of inventions that can be used to innovate

Figure 1. Innovative capacity (total number of legally valid invention patents available) 1880-1995 (USA)

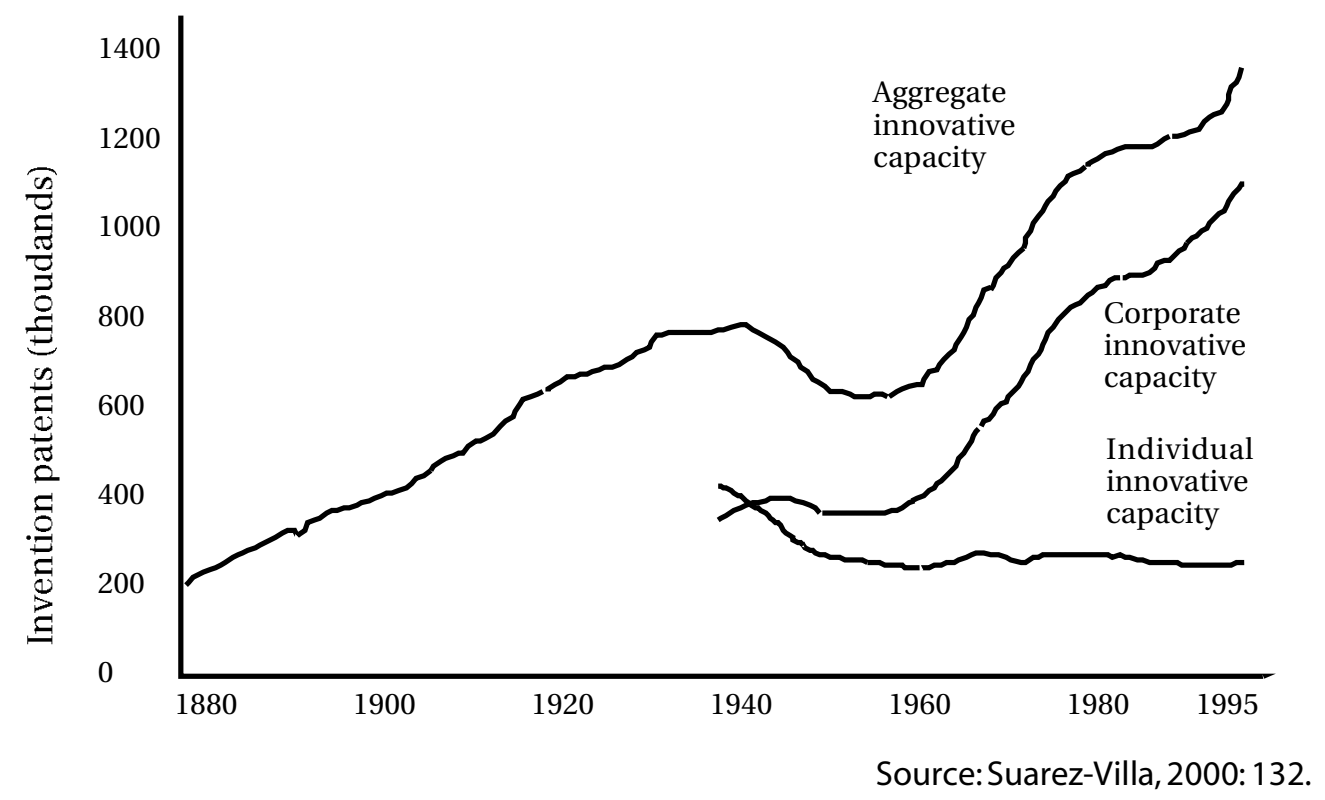


(or, in other words, to put an invention to some purpose) in any field (see SuarezVilla, 1990; 2000: chapter 3). It is therefore a gross societal indicator of the aggregate stock of inventions available for use as innovations in any given year.

The accumulation of inventions increased rapidly during most of the twentieth century and particularly so after the 1950s. Although the data shown in Figure 1 pertains to the United States, in most every advanced nation the rise in invention patenting was also unprecedented, attaining levels never reached before. Historical works on the nineteenth and twentieth centuries have shown how the accumulation process unfolded, based not only on patenting but also on other indicators (see Jewkes et al., 1959; Schmookler, 1966; Mensch, 1979; von Hippel, 1988; Cantwell \& Barrera, 1997; Gaudillière \& Löwy, 1998). The growing importance of patenting during the twentieth century was itself a reflection of the rising value of technological knowledge as a commodity (see Warshofsky, 1994; Mandeville, 1996; Rivette \& Kline, 2000). If technological knowledge had not acquired increasing importance, patenting would not have been sought to the extent that it was during the twentieth century. Today, the incentives to patent are more important than ever. By and large, the current rush to turn most any tacit knowledge into a patent is itself a product of the rising commodification of knowledge and creativity, upon which the emergence of technocapitalism depends.

Given that existing inventions are often the source or point of departure for new ones, the rapid accumulation of inventions during the twentieth century takes on added importance. The larger the stock of existing inventions, the more likely it is that new ones will be created and that the stock will in turn grow larger. The reproduction of technological knowledge (which is one of the phenomena underpinning the rise of technocapitalism) feeds right into this dynamic, since the new inventions it generates enlarge the stock or mass of existing ones. The rapid accumulation of inventions also contributed toward the more expansive commodification of technological knowledge of the last four decades of the twentieth century. A larger stock of inventions from which to learn or draw upon by itself made commodification more valuable.

At the same time, the vast and increasing accumulation of inventions of the late twentieth century provided a springboard from which various processes of globalisation started. One of the results is the globalisation of intellectual property issues, including patenting. The pressures to globalise and commodify intellectual property are now reaching into the most remote parts of the world, seeking to standardise any and all property rights related to technological knowledge. In some respects, this movement is reminiscent of earlier efforts to globalise industrial production standards during industrial capitalism, through the spread of Frederick Taylor's and Henry Ford's ideas (see Kanigel, 1997; Tolliday, 1998).

The spread of invention patenting through new activities and industries in recent years also reflects the growing importance that the commodification of knowledge is taking up in contemporary society. The acquisition of patents for "business methods" and in particular those related to Internet commerce is an 
example of this trend. Another example is the acquisition of patents in the field of genetics, with biotechnology companies obtaining patents on decoded genes that can be used to develop new medications (see Acharya, 1999; Robbins-Roth, 2000). Genetically-based medications and therapies are very likely to revolutionize pharmaceuticals and medical practice itself, by targeting illnesses through an individual's specific genetic make-up, thereby rendering the mass production of many pharmaceuticals obsolescent. This is turning some biotechnology companies into gene decoding factories, with the sole objective of obtaining as many patents on decoded genes as possible, so that the patents can then be licensed to other parties. Such companies thus become both laboratories and clearing houses of genetic knowledge, providing a glimpse of how the commodification of knowledge may evolve to become the commodification of life itself.

In sum, the rapid accumulation of inventions during the twentieth century was of fundamental importance to the rise of technocapitalism. To the extent that one can provide any insights on this emerging phenomenon and its significance for the twenty-first century, it is essential to recognise the importance of the vast pool or stock of inventions from which many current discoveries and innovations emerged. This long process of accumulation is supporting the formation of many new fields and activities, such as biotechnology, nanotechnology, molecular electronics, bioinformatics and quantum computing, which promise to be at the core of new technological developments and industries during this century.

\section{Infrastructure}

The rapid accumulation of knowledgesensitive infrastructure is a second major support behind the emergence of technocapitalism. The stock of such infrastructure rose substantially during the second half of the twentieth century in most every advanced nation. Its rapid accumulation provided another platform that, together with the accumulation of inventions, impelled the reproduction of knowledge and its commodification to higher levels. The accumulation of knowledge-sensitive infrastructure also supported the spread of technological and scientific education in very important ways. Without it, the training of new cadres of scientists and technologists would have been severely undercut.

The rise of public infrastructure spending, shown in Figure 2, contributed much to the rapid accumulation of this important support of technocapitalism. Such spending is directly related to accumulation, and reflects both the magnitude and intensity of the process. Total public spending on infrastructure in the United States (including all communication and educational facilities) rose ten-fold between 1945 and 1995. Most significantly, spending on public educational infrastructure (including all schools, universities and laboratories) increased fiftyfive times during the same period of time (see Suarez-Villa, 2000: ch.5). These data, however, exclude spending on private educational infrastructure, which in the United States was considerable over the years after 1945, given the large number of private schools and universities. Unfortunately, such data have never been completely accounted for or tabulated, 
and it is obvious that the increase in total (public and private) educational infrastructure spending was considerably greater than that shown in Figure 2.

Although the data shown in Figure 2 are only for the United States, other advanced nations experienced similar or even more impressive increases, particularly where infrastructure was severely damaged during the Second World War. Educational infrastructure spending, in particular, contributed to a substantial accumulation of physical facilities devoted to science and technology over the years since the late 1940s, in most every advanced nation. Such spending and accumulation also con- tributed to the reproduction of knowledge, by providing the physical (or static) resources where it could be acquired, exchanged and diffused. As with the accumulation of inventions, the rapid and large-scale accumulation of infrastructure (and of educational infrastructure, in particular) provided a platform of facilities from which learning and the diffusion of knowledge could occur.

A discussion of the accumulation of infrastructure cannot be limited to physical (or static) infrastructure, however. There is a second function of infrastructure, the dynamic one, which also deserves consideration. Dynamic infrastructure helps accumulation and the

Figure 2. Public infrastructure expenditures 1920-1995 (USA), in constant 1958 billion \$US.

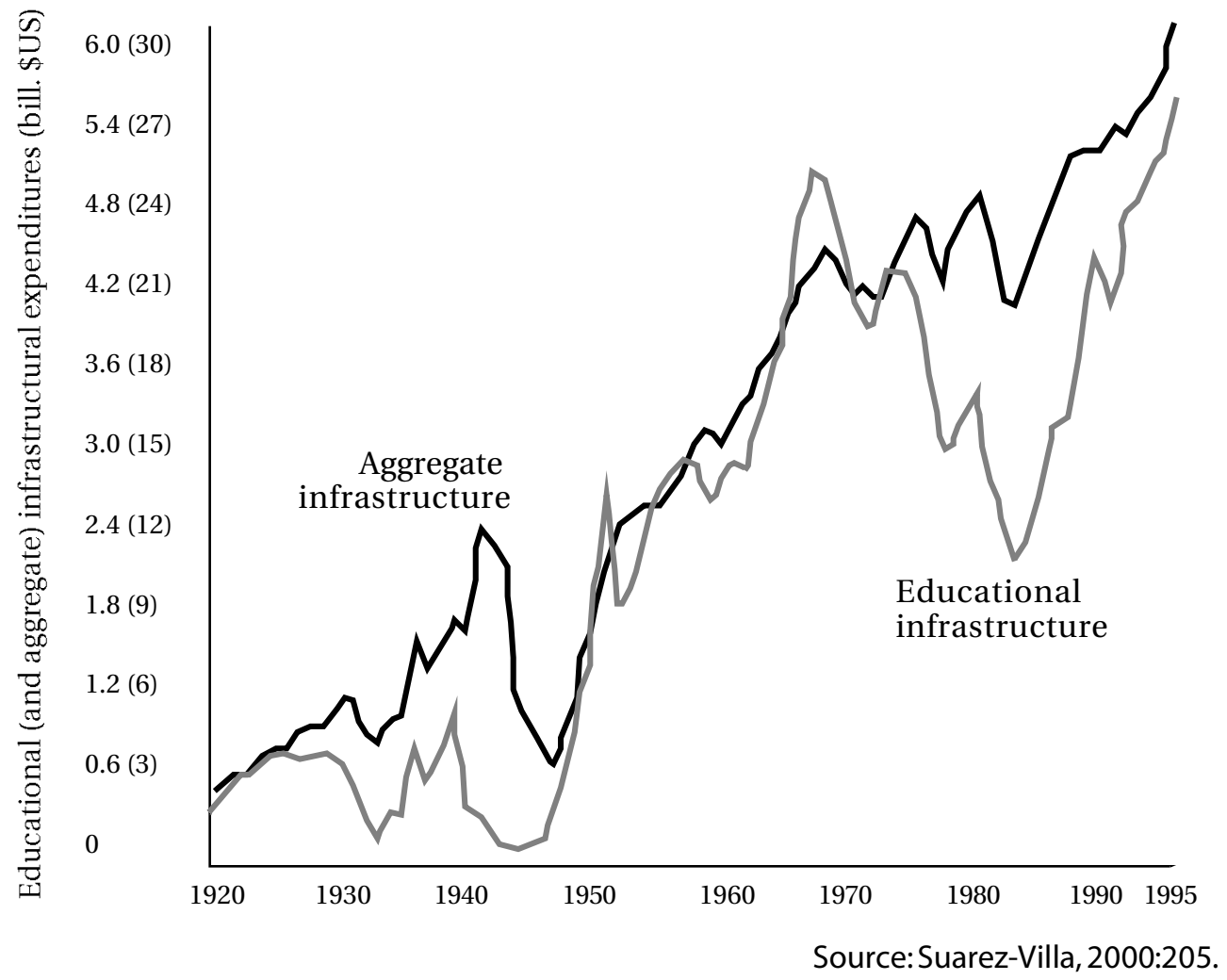


reproduction and commodification of knowledge, for example, by providing opportunities to experiment, establish contact, interact and diffuse knowledge (see Suarez-Villa, 2000). The dynamic functions are intangible and rely on change to generate new ideas, subvert established ones or recombine different strands of knowledge. Balance and equilibrium are therefore enemies of the sort of continuous transformation that dynamic infrastructure supports. Another example of a dynamic infrastructural function are the networks of researchers that collaborate on projects, and which must generate new ideas to accomplish their objective. The embedding of inventors in local communities that have supportive values and attitudes, such as an appreciation of novelty or a tolerance of failure, also illustrate how dynamic infrastructure helps support invention and the reproduction of knowledge.

It must be noted, however, that the dynamic functions of infrastructure cannot occur without the static (or physical) one. Physical or static infrastructure must be accumulated in order for the dynamic functions to occur. The former is a prerequisite for the latter. Nevertheless, the two have very different characteristics and functions to perform. Whereas for static or physical infrastructure stable access is essential for it to succeed in supporting invention, the dynamic functions on the other hand thrive on frequent change. Without change, the interactions and crossfertilisation of ideas that are essential to reproduce knowledge cannot occur. Thus, the static and dynamic functions of infrastructure complement one another, and are essential for the kind of invention and innovation on which the emergence of technocapitalism depends.

A vast accumulation of knowledgesensitive infrastructure is another important phenomenon supporting the emergence of technocapitalism. Infrastructure is often overlooked or taken for granted whenever scientific or technological development is considered. Nevertheless, the enormous accumulation of knowledge-sensitive infrastructure is an important contributor to the vast number of discoveries from which new fields and activities are being spawned. Moreover, the accumulation of infrastructure is becoming more important in an age when laboratories and equipment can often determine the success of research projects, in contrast with the times when inventors working alone in sheds or basements could come up with significant discoveries with rudimentary equipment. Thus, the accumulation of infrastructure has become a decisive factor in the quality and quantity of new discoveries that can be found. At the same time, its accumulation is an essential prerequisite for the reproduction and commodification of knowledge, particularly in the complex fields and research activities, which are the hallmark of technocapitalism.

\section{Processes of Diffusion and Reproduction}

The second set of phenomena supporting the emergence of technocapitalism involves those related to processes of diffusion and reproduction of technological knowledge. Four significant phenomena can be considered at this time, although the paucity of data poses many challenges to their documentation. By 
and large, these phenomena can be linked more directly to the commodification of knowledge, mainly because most of them involve activities that are either a prerequisite for or very much a part of the search for exchange value that characterises our knowledge-driven economies.

Most of the phenomena of diffusion and reproduction also have a direct role in the codification of new knowledge. As such, they contribute to reveal its exchange value more clearly than the accumulation processes considered previously. In part, the emergence of the socalled new economy, which relies on the exchange value of knowledge by creating new activities based on information technology, is a by-product of these phenomena. The often-cited knowledge society is also largely a product of the phenomena to be considered in this section, given its reliance on the diffusion of knowledge to generate new kinds of social relations. Taking a broad perspective, therefore, both the knowledge society and new economy paradigms are by-products of the forces that support the emergence of technocapitalism.

\section{Massification of Education}

The massification of technological education is an important phenomenon behind the emergence of technocapitalism. Such education was by and large reserved for elites in most nations in the nineteenth century and through the first half of the twentieth century. Only a very small fraction of all eligible individuals, not to mention the population at large, could hope to have access to the sort of education that would provide a capacity to invent or innovate. Technological knowledge was therefore largely circumscribed to a small and in-bred group of specialists in most every nation, who typically controlled both access and the diffusion of knowledge in their field.

However, the spread of industrial capitalism required some workers and other personnel to be technically trained in order to operate the factories that were so typical of that era. In time, such training and the experience that was acquired through work spawned new technical fields, and it gradually began to open up technical training for the masses. Technical institutes were created in many nations for that purpose, some of which later on became full-fledged universities. Social, political and economic change then opened up access to university education in some societies (see, for example, Geiger, 1986, 1993; Lucas, 1994; Graham \& Diamond, 1997). The recognition gradually began to take hold that education, and particularly technological and scientific education, should not be a class-based privilege or the preserve of elites, but that everyone qualified should have some access to it.

Work on the history of science and technology has already provided many insights on aspects related to the spread of technological education and its increasing access to the masses (see Hall, 1962; Kuhn, 1962; Lucas, 1994; Lenoir, 1997). An important point is, however, that the massification of technological education has provided a fundamental base upon which technological knowledge and creativity can be built and reproduced. Thus, technocapitalism, the large-scale reproduction of technological knowledge and its very commodification depend greatly on this phenomenon. 
Data on the opening up of access to education is sparse, but some comparative insights on its magnitude can nevertheless be found. Between 1913 and 1995 , for example, the average number of years of higher education in the United States rose ten-fold (from 0.2 in 1913 to 2.0 in 1995) (OECD, 2000; SuarezVilla, 2000). Other advanced nations also experienced substantial increases in the same indicator. France, for example, saw a nine- fold increase in the average number of years of higher education for its population, while in Britain and Germany this indicator rose by five and four times, respectively, during the same period of time. In Japan, the increase in the average number of years rose six times between 1913 and 1995. By and large, however, the largest increases in this indicator occurred after the late 1940s, when access to higher education was expanded in many advanced nations (see Clark, 1987; Geiger, 1993; Lucas, 1994).

The massification of education is now being taken a step further with the "distance learning" approach being adopted by many universities, even the most elitist ones. The creation of "e-diplomas" in the United States that can be acquired over the Internet, will likely make a university education more accessible than ever before. Most anyone with some qualification will be able to pursue a university degree in many fields. It is uncertain how many areas of technology will be reached by this movement toward further massification, but it is likely that education in many fields of technology will be made much more accessible. Perhaps only those fields, which require supervised or intensive laboratory work will find it harder to join the distance learning movement. However, it is likely that suitable adaptations may be found even for them, through local arrangements or remote-controlled conditions. The flexibility being introduced by this new form of massification is an important feature, allowing many individuals to pursue a university diploma from their homes or while they hold employment. Its characteristic flexibility and adaptive qualities also reflect the growing importance that knowledge is gaining as a commodity, along with its rising exchange value.

\section{Diffusion of Knowledge}

The diffusion of knowledge is a vital link between the massification of technological education and the commodification of knowledge. Over the past decade it has been aided much by the spread of information technology into almost every human activity. It is important, however, to differentiate knowledge from information. Information is usually shallow and confers only a very temporary advantage, when it confers any at all. Knowledge, on the other hand, often provides a lasting advantage and requires much effort and persistence over long periods of time to be mastered. Knowledge therefore has potentially greater exchange value than information whenever it can be commodified and put to some profitable use.

There is no doubt that the diffusion of knowledge has accelerated over the past two decades. Not only have the number of publications in various fields of technology increased rapidly, but it is now possible to publish electronically and receive almost immediate feedback. Priority of appropriation and recogni- 
tion are much easier to obtain, as massive diffusion makes it possible to reach almost everyone working in any given area of technology. This sort of speed has accelerated the reproduction of knowledge, by promoting the rapid exchange and cross-fertilisation of ideas. Access to diffusion has also increased enormously through information technology. Socioeconomic disparities, however, remain an important obstacle to diffusion, both within advanced nations and on a global scale. In the emerging technocapitalist order, those who fall behind in the technology race, both nationally and globally, may find it very difficult to catch up, given the cumulative and "winner-takes-all" character of discovery and appropriation. Thus, commodification also acquires a prioritary character in technocapitalism. As a result, whenever prioritary knowledge is commodified, it is bound to have much greater exchange value.

As with so many other aspects of technology, the scarcity of data to provide complete insights on the diffusion of knowledge remains a challenge. Only occasional bits of information can be obtained and even then much of it is rather incomplete. One potential indicator of the expansion of diffusion of knowledge is the number of scientific and technological articles published per capita during any given period of time. In the United States, for example, this indicator increased by almost 30 percent between the middle 1970s and the early 1990s (OECD, 2000; Suarez-Villa, 2000). Other advanced nations experienced larger increases. In Germany, for example, the number of scientific and technological articles published per capita rose by 105 percent, while in Britain and France its increase was 60 and
50 percent, respectively, during the same period of time. In Japan, it increased by 90 percent. The United States' lower rate of increase is misleading, however, because during much of the 1970s and 1980 s its lead in per capita scientific articles published was between 28 and 360 percent higher than those of Japan, Germany and France (Suarez-Villa, 2000: chapter 1). Thus, starting from a much lower relative base of published articles largely accounted for the larger rates of increase of the other nations noted above.

The accumulation of recognition and experience are also important for the diffusion process, since better-known individuals tend to attract more attention to their work and thereby enjoy stronger diffusion. Progress over an individual's life cycle also helps create an advantage, since recognition bears a direct and positive relationship with age (see Stephan \& Levin, 1992). Thus, nations with a larger pool of older and wellrecognised scientists and researchers tend to have a stronger comparative advantage in diffusion. Not surprisingly, perhaps, the same nations are typically those with the deepest and most dynamic processes of accumulation discussed previously. A high degree of "path dependence" can therefore be found in diffusion, where nations that advance furthest as major sources of diffusion (as in the case of the United States) preserve their advantage over time.

In general therefore, an acceleration in the diffusion of knowledge is an important support for the rise of technocapitalism. Nations that were important sources of diffusion during the second half of the twentieth century have tended to preserve their advantages, thus sup- 
porting the emergence of new technologies. Those nations also happened to be the ones that experienced a rapid accumulation of inventions and infrastructure, along with major increases in the massification of technological education, revealing a potentially (but perhaps not surprisingly) strong linkage between accumulation, educational access and diffusion.

\section{Corporatisation of Knowledge}

The pervasive corporatisation of technological knowledge is a distinctive feature of our time. The vast majority of new technologies, and particularly the most valuable ones, are today spawned within corporate structures. In many ways, this situation reflects the extent to which technological knowledge has been commodified. In the companies and sectors that are most representative of technocapitalism, technological knowledge and creativity are the most important resources, much as raw materials and labour power were for the factories of industrial capitalism.

Research and development (R\&D) departments have acquired more importance than ever within corporate structures. In every new technology sector, such as biotechnology, microelectronics, bioinformatics, software, nanotechnology or advanced computing, $R \& D$ priorities have substantial weight in the formulation of corporate strategy. It is plausible, for example, to say that in most biotechnology companies R\&D is "everything," and that companies live or die by the accomplishments (or lack thereof) of their research agendas (see Orsenigo, 1989; Acharya, 1999; RobbinsRoth, 2000). This is in stark contrast with the situation of most industrial capitalist companies, where production and marketing were the most important concerns of corporate strategy (see Chandler, 1990; Kanigel, 1997; Tolliday, 1998).

The corporatisation of knowledge is a major force behind the rapid accumulation of inventions. In Figure 1, the shape of the trend for the total number of valid invention patents held by corporations (the corporate innovative capacity) is revealing. The strong similarity between the corporate and aggregate trends is an indication of how strongly the accumulation of inventions relies on corporate research (see Suarez-Villa, 2000: ch.3). By contrast, the individual innovative capacity trend, which represents the total number of valid patents held by individual inventors (rather than corporations) remained stagnant since the 1940s. It should not come as a surprise, therefore, that individual inventors, working independently and supported by their own means, have become less important than ever for the advancement of technology.

Part of the reason for this development is the increasing need of corporate capitalism to reproduce and commodify technological knowledge in more efficient ways. Only when knowledge can be reproduced can it become a commodity. The very act of reproduction ends up making knowledge into a commodity, as it turns the creation of new (tacit) knowledge from having only utility value into something (an idea, product or process) that has exchange value. Only by corporatising inventive knowledge and reproducing it within the context of $R \& D$ programmes can a company hope to turn it into a commodity. Individual inventors working on their own are a poor 
way to reproduce or commodify such knowledge, much as the independent craft shops of the eighteenth century were not the most effective way to commodify labour.

The means of reproducing knowledge are varied and can include, for example, the recombination of existing ideas or inventions. Another way in which reproduction can occur is by improving or evolving an existing product to make it work better. Recasting an existing idea or product to fit new uses, often in a different field from that for which it was originally made, can also be a means of reproduction. All of these means can achieve reproduction within the corporate context through, for example, collaboration or alliances between groups of researchers. In this context, however, the reproduction of knowledge has little purpose unless it can result in some exchange value (and ultimately profits) for a corporate entity.

In the process of reproduction, laboratories and other equipment become commodities that are essential in order to reproduce knowledge and turn it into a commodity. R\&D laboratories and equipment are part of the corporate infrastructure that is necessary to systematise the process of reproduction. Their use value to the corporation is important, therefore, but mainly because they help reproduce and commodify knowledge to extract some kind of exchange value out of it. R\&D laboratories are therefore only a utility to a corporation, to be used as needed or as frequently as possible to reproduce knowledge and turn it into a commodity. In a way, therefore, a given commodity (R\&D laboratories) is used to reproduce another commodity (technological knowl- edge), not unlike the association between production equipment and labour under industrial capitalism (see Sraffa, 1960).

The rising corporatisation of technological knowledge and creativity also reflects the global expansion of many companies during the last two decades of the twentieth century. The reproduction and commodification of technical knowledge within corporate contexts has become more urgent, as companies compete fiercely for market share around the world. By accelerating the reproduction of knowledge (and thus, eventually, the output of new inventions and innovations), companies can hope to compete more effectively in a world where national trade barriers are rapidly collapsing. This urgent need is also part and parcel of the emergence of technocapitalism, where new technologies diffuse rapidly across boundaries, and where their appropriation (as property rights to a new invention) must be zealously secured for any company to be able to profit from their use.

\section{Continuous Invention and Innovation}

One of the products of the rising corporatisation of knowledge is the pressing need to sustain invention and innovation in a continuous or systematic way. Corporate objectives aimed at extracting more exchange value out of technological knowledge drive the need to engage in continuous invention and innovation. To do so, firms have turned their R\&D departments into operations whose overarching concern is to reproduce knowledge, by finding new discoveries that can be turned into products. Occasionally, discoveries may be novel enough to garner a patent award. Failures to find 
such discoveries are common, but the search for successful ones must nevertheless go on continuously, to increase the probability of finding them (see McKelvey, 1996; Robbins-Roth, 2000). This is occurring now to a degree that was unknown in the companies that were typical of industrial capitalism, where $R \& D$ departments tended to be loose or detached operations, and innovation was more often a result of serendipity than of systematic research.

The systematisation of research is essential for companies that depend heavily on turning out new inventions and innovations at a rapid pace. Systematisation can reduce the risk and uncertainty involved in finding new discoveries, or in extracting exchange value from what previously only held some use value. Continuous or systematic innovation also requires a great deal of programming, organisation and viable agendas. Much continuous innovation therefore involves substantial organisational effort, which requires logistical support, coordination with other corporate units, and accountability on the spending of resources. Continuous innovation also typically involves group efforts, such as collaboration, the sharing of ideas, and executing tasks that can lead to new (and potentially profitable) findings.

Continuous innovation can also occur outside the corporate framework, although this is very infrequent. Mostly where expensive laboratories or facilities are not required can such efforts occur successfully. A group effort is typically involved, pooling the talents of many researchers. An example of this approach is the "open source" software movement involving the design and de- velopment of the Linux software system (see Holtgrewe \&Werle in this issue; also Wayner, 2000; Raymond, 1999). A selforganising, atomistic effort involving thousands of software programmers working online on their own spare time but sharing a common framework is at the core of this process of continuous innovation. By rejecting individual or group appropriation and making the software and all its improvements available freely on the Web, they therefore provided only utility value for the new knowledge they generated. Thus, continuous innovation can occur outside corporate structures, although it is most commonly found within them.

Evidence on the increasing importance of continuous invention and innovation is becoming more common, as competition drives many companies to depend more on new technologies (see Suarez-Villa, 2000: ch.2). Figure 3 shows the capacity increases for microchips and magnetic memory disks between 1986 and 1997. Rising capacity frontiers for both of those products indicate the effect of continuous innovation on their producers. The rapidly expanding increases in performance, also known as "Moore's Law" (named after the semiconductor engineer who discovered them), indicate that a doubling of capacity in microchips occurred every eighteen months. Exponential increases in performance (so substantial that a logarithmic scale had to be used in Figure 3), indicate how systematic research and experimentation, made essential by fierce competition between companies within both of the two sectors, overcame serious obstacles to increase product performance at a rapid pace (see Ceruzzi, 1998; Buderi, 2000). 
Figure 3. Capacity increases in microchips and magnetic memory disks

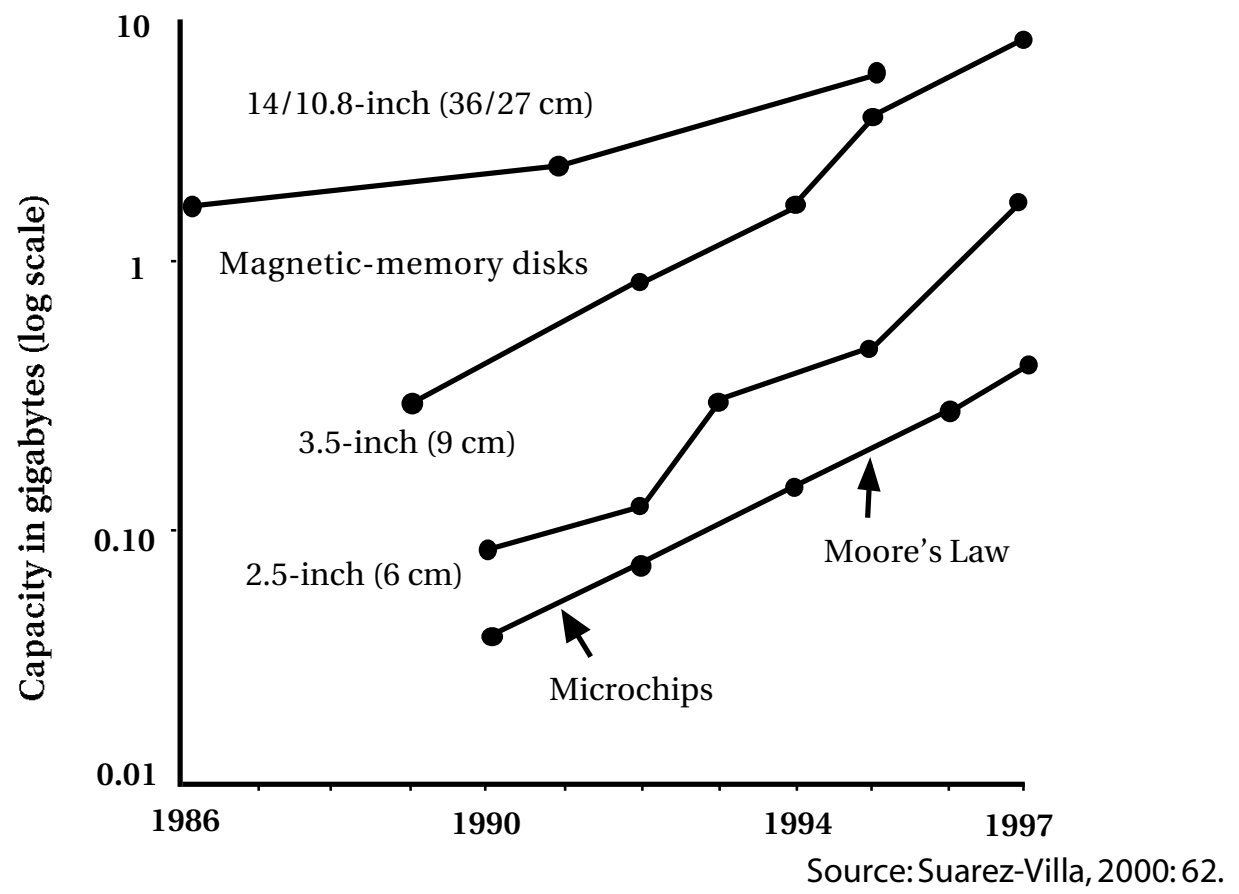

The increasing importance of continuous innovation has also led to the spread of predatory tactics between companies that depend greatly on new technologies. Pre-empting competitors by introducing similar products, often based on imitation, has become more frequent than ever. To implement such tactics, many companies have created dualistic research operations, where "first-mover" or basic (prioritary) research coexists with "second-mover" innovation (see Suarez-Villa, 2000: ch.2). The latter is then aimed at imitation and moving products from lab to market rapidly, in order to either pre-empt competitors or fend off their predatory advances. In many cases, having a "defensive" capability, such as second-mover research, is considered highly desirable by some stock market analysts and investors. Firms that do not have such capabilities are often viewed as disadvantaged, since they may find themselves short-changed in today's aggressively competitive business culture.

Shrinking lead times between the market launches of new products and those of their first rival are an indication of the more aggressive strategies spawned by continuous innovation. Figure 4 shows how the lead times between the introduction of several major new medications and those of their first direct competitors shrank during the past three decades. Such a rapid reduction in lead times was not unique to the pharmaceutical industry, but can also be found for most any technology-intensive sector today. The spread of aggressive compe- 
tition in technology-intensive activities has therefore become an accepted (if not downright common) feature of corporate business, and particularly so in those that depend greatly on producing a continuous stream of innovative products.

The rising importance of continuous innovation is part and parcel of the emergence of technocapitalism. To a great extent, continuous innovation reflects the achievement of a faster reproduction of knowledge and creativity within corporate structures. Turning tacit knowledge into explicit forms, standardising and codifying it is at the core of this rapid process of reproduction which continuous innovation has spawned. As the pace of knowledge reproduction increases, it seems reasonable to expect that a faster and more intense commodification of knowledge will follow. Underlying this dynamic is the attempt (ever more aggressive and competitive) to extract exchange value from knowledge in faster and ever more profitable ways.

\section{Conclusion}

The reproduction and commodification of knowledge are at the core of the emerging technocapitalist era. Knowledge and its transformation into exchange value in ever faster and more valuable ways is what distinguishes this

Figure 4. Lead times between market launch of new medications and the appearance of their first competitor

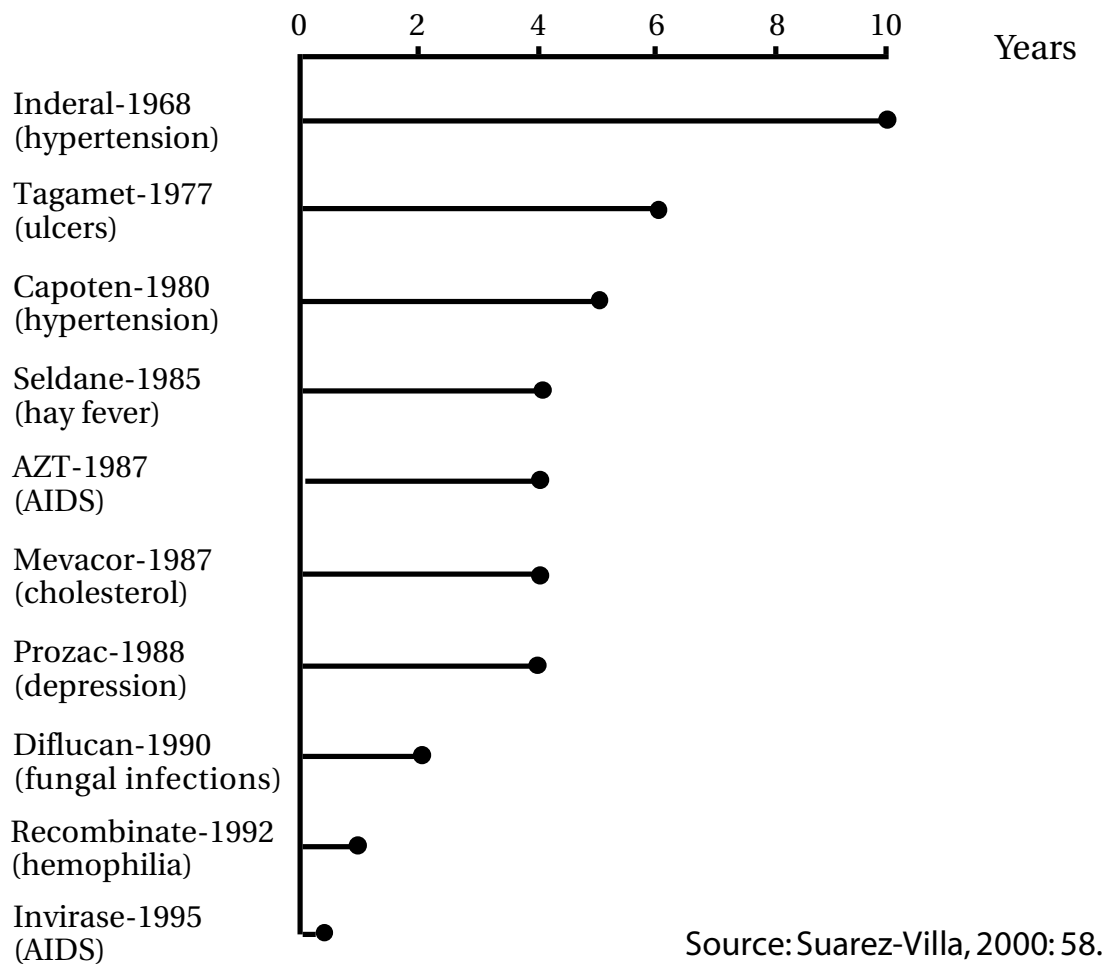


emerging new epoch from industrial capitalism. This process will likely render many social structures obsolete, as some organizations, sectors and activities fall by the wayside of history and are replaced by new instruments of accumulation and power. We do not yet know the full effects or even the complete profile of this emerging new era, but its impacts are likely to reach into every aspect of life and work.

We may already see some signs of those effects in, for example, the way corporate structures are changing to encompass more knowledge and innovation. The most valuable corporations on earth today are already largely built around invention, innovation and knowledge. Accumulating technological knowledge and appropriating it are already seen as the most important means to wealth and power. Disparities in access to new knowledge may well become more profound, as the global technology race accelerates and the have-nots of our world are left farther behind. The race to appropriate new knowledge and its "winner-takes-all" character are already increasing social tensions in many advanced societies. Many entrenched social and cultural values are being obliterated by the unquenchable thirst for the rewards offered by this new paradigm.

Many questions remain open at this time but few can be answered in any complete way. What seems certain is that the new era may pose substantial challenges to our social identities and the way we view work, wealth and power. Technocapitalism is likely to provide many tools with which to reshape human culture, social relations and economic action. But, in the end, they will be just means. It will be up to humanity to be able to tell the means from the ends. Any confusion of these two very different entities can result in identity crises the likes of which humanity has never experienced. It will be up to us to define which ends we must pursue and which means we must use. Hopefully, this contribution will inspire other researchers to look into the character and attributes of this emerging new era.

\section{References}

Acharya, R.

1999 The Emergence and Growth of Biotechnology. Northampton, Massachusetts: Edward Elgar.

Buderi, R.

2000 Engines of Tomorrow: How the World's Best Companies are Using their Research Labs to Win the Future. New York: Simon and Schuster.

Cantwell, J. \& Barrera, M. P.

1997 The History of Technological Development in Europe and the United States. Oxford: Oxford University Press.

Ceruzzi, P. E.

1998 A History of Modern Computing. Cambridge, Massachusetts: MIT Press.

Chandler, A. D.

1990 Scale and Scope: The Dynamics of Industrial Capitalism. Cambridge, Massachusetts: Harvard University Press.

Clark, B. R.

1987 The Higher Education System: Academic Organization in Cross- National Perspective. Berkeley: University of California Press.

Gaudillière, J.-P. \& Löwy, T.

1998 The Invisible Industrialist: Manufactures and the Construction of Scientific Knowledge. New York: St. Martin”s.

Geiger, R. L.

1986 To Advance Knowledge: The Growth of American Research Universities, 19001940. New York: Oxford University Press.

1993 Research and Relevant Knowledge: American Research Universities since WorldWar II. New York: Oxford University Press. 
Graham, H. D. \& Diamond, N.

1997 The Rise of American Research Universities: Elites and Challengers in the Postwar Era. Baltimore, Maryland: Johns Hopkins University Press.

Hall, A. R.

1962 The Scientific Revolution, 1500-1800. London: Longman.

von Hippel, E.

1988 The Sources of Innovation. Oxford: Oxford University Press.

Jewkes, J., Sawers, D., \& Stillerman, R.

1959 The Sources of Invention. NewYork:W. W. Norton.

Kanigel, R.

1997 The One Best Way: Frederick Winslow Taylor and the Enigma of Efficiency. New York: Viking.

Kuhn, T. S.

1962 The Structure of Scientific Revolutions. Chicago: University of Chicago Press.

Lenoir, T.

1997 Instituting Science:The Cultural Production of Scientific Disciplines. Stanford, California: Stanford University Press.

Lucas, C. J.

1994 American Higher Education: A History. New York: St. Martin's.

Mandeville, $\mathrm{T}$

1996 Understanding Novelty: Information, Technological Change, and the Patent System. Norwood, New Jersey: Ablex.

McKelvey, $\mathrm{M}$.

1996 Evolutionary Innovations: The Business of Biotechnology. Oxford: Oxford University Press.

Mensch, G.

1979 Stalemate in Technology. Cambridge, Massachusetts: Ballinger.

OECD

2000 Statistical Compendium. Paris: OECD. Orsenigo, L.

1989 The Emergence of Biotechnology. New York: St. Martin's.

Raymond, E. S.

1999 The Cathedral and the Bazaar: Musings on Linux and Open Source by an Accidental Revolutionary. Cambridge Massachusetts: O'Reilly

Rivette, K. G. \& Kline, D.

2000 Rembrandts in the Attic: Unlocking the Hidden Value of Patents. Boston: Harvard Business School Press.
Robbins-Roth, C.

2000 From Alchemy to IPO: The Business of Biotechnology. Cambridge, Massachusetts: Perseus.

Schmookler, J.

1966 Invention and Economic Growth. Cambridge, Massachusetts: Harvard University Press.

Sraffa, P.

1960 Production of Commodities by Means of Commodities. Cambridge: Cambridge University Press.

Stephan, P. E. \& Levin, S. G.

1992 Striking the Mother Lode in Science: The Importance of Age, Place, and Time. New York: Oxford University Press.

Suarez-Villa, L.

1990 "Invention, Inventive Learning, and Innovative Capacity." Behavioral Science 35 (4), October: 290-310.

2000 Invention and the Rise of Technocapitalism. Lanham, Maryland, New York and Oxford: Rowman \& Littlefield

Tolliday, S., (ed.)

1998 The Rise and Fall of Mass Production. Vols. 1 and 2. Northampton, Massachusetts: Edward Elgar.

Warshofsky, F.

1994 The Patent Wars: The Battle to Own the World's Technology. New York: John Wiley.

Wayner, $\mathrm{P}$.

2000 Free for All: How Linux and the Free Software Movement Undercut the High-Tech Titans. New York: Harper Business.

Luis Suarez-Villa

School of Social Ecology

University of California, USA

lsuarez@uci.edu 